\title{
APPLICATION OF THE DESTINATION APPROACH AS AN IMPEDIMENT TO THE DEVELOPMENT OF GAMBLING POLICY AND LAW IN SOUTH AFRICA
}

\author{
Segoane Lawrence Monnye \\ B Proc LLB LLM LLD \\ Admitted Attorney and Senior Lecturer \\ University of South Africa (UNISA)
}

\section{SUMMARY}

Gambling in South Africa, which the National Gambling Act sanctions, ${ }^{1}$ continues to be a flourishing economic activity. The policy approach to gambling has always been to keep gambling venues a distance away from communities because of the negative consequences of gambling, also referred to as problem gambling and the negative moral stigma associated with gambling. The goal of this policy, which is also referred to as the "destination approach" is to circumvent impulse gambling, which may lead to problem gambling. The destination approach can be credited with the development and flourishing of casino gambling resorts throughout South Africa and at present, such resorts serve as artificial tourist attractions.

However, the rationale for maintaining the destination approach in gambling policy and the law is no longer sustainable for a number of reasons. Firstly, the increasing incidence of gambling problems, secondly, there is little or no research that indicates the efficacy of the destination approach in curbing problem gambling and thirdly, the emergence of new gambling platforms such as interactive/online gambling means that gambling is conveniently available at the click of a mouse. Furthermore, there is growing evidence of casino operators relocating to areas with a high frequency of customers, such as shopping malls, which undermines the destination approach.

Nevertheless, both the National Gambling Policy of 2016 and the National Gambling Amendment Bill of 2016 persist in maintaining the destination approach as a means of limiting accessibility to gambling opportunities and ultimately minimising problem gambling. This is despite the existence of strategies for the prevention of problem gambling. It is the author's submission that maintaining and applying the destination approach in gambling policy and law, not only hinders competition in the gambling industry but also poses a threat to the enjoyment of gambling as a recreational economic activity, as listed in Schedule 4 of the Constitution. Destination gambling has little or no effect on problem gambling.

National Gambling Act 7 of 2004. 


\section{$1 \quad$ INTRODUCTION}

South Africa's gambling policy and law subscribe to the "destination approach", which seeks to locate gambling venues a distance away from communities. This is evident from the Cabinet-approved National Gambling Policy of 2016, ${ }^{2}$ which calls for the maintenance of the destination approach to gambling, in order to preserve casino gambling. To prevent the demise of the destination approach to gambling, the National Gambling Policy of 2016 places an embargo on the introduction of any new forms of gambling activities "which may require a policy shift in regard to destination approach to gambling". ${ }^{3}$ The purpose of the destination approach is to limit the proliferation of gambling opportunities and accessibility to society, with a view to prevent problem gambling. ${ }^{4}$ Problem gambling is a term encompassing a range of negative consequences - from mild to severe resulting from uncontrollable gambling behaviour. ${ }^{5}$

The emergence of new forms of gambling has brought the relevance of the destination approach in the modern world to the forefront such as interactive gambling and urban redevelopment, which incorporates gambling amenities in major shopping zones. This means that accessibility to gambling no longer depends on a physical visit to any casino premises.

This article conceptualises the application of the destination approach in terms of the National Gambling Act 7 of 2004, critiques its relevance in light of the relocation of gambling licences to affluent residential areas integrating new business developments, assesses the impact of the destination approach on the minimisation of problem gambling, and ultimately challenges the rationale of the National Gambling Policy to maintain the destination approach, despite its obvious inability to curb the proliferation and accessibility of gambling opportunities and ultimately problem gambling.

\section{OVERVIEW OF GAMBLING REGULATION IN SOUTH AFRICA}

In terms of Schedule 4 of the Constitution, gambling is listed as a legitimate activity falling within the concurrent legislative authority of both the national and provincial spheres of government. ${ }^{6}$ The inclusion of gambling as a lawful

2 Department of Trade and Industry National Gambling Policy, 2016, GN 389 in GG 39887 of 2016-04-01 2-11.

3 Department of Trade and Industry National Gambling Policy 9.

4 Young, Tyler and Lee Destination-Style Gambling: A Review of Literature Concerning the Reduction of Problem Gambling and Related Social Harm Through the Consolidation of Gambling Supply Structures (2007) 1.

5 Whyte and Dunning "A Public Policy Framework for Minimizing Problem Gambling-Related Harm: the PETTER Model" 2016 6(2) UNLV Gaming LJ 199200.

6 The Constitution of the Republic of South Africa, 1996 (the Constitution). S 104(1)(b)(i) of the Constitution of the Republic of South Africa of 1996 provides as follows: "The legislative authority of a province is vested in its provincial legislature, and confers on the provincial legislature the power to pass legislation for its province with regard to any matter within a functional area listed in Schedule 4". Schedule 4, entitled "Functional Areas of Concurrent 
activity means that gambling can be pursued as a trade, occupation or profession in accordance with the right that is enshrined in the Bill of Rights. ${ }^{7}$ This recognition by the Constitution has allowed gambling to develop as an economic recreational activity, which is capable of generating revenue for governments through taxation and licence fees ${ }^{8}$ and thereby weathering its immorality overtones. ${ }^{9}$ The National Gambling $\mathrm{Act}^{10}$ primarily governs gambling ${ }^{11}$ in conjunction with the provincial laws for each respective provincial government. ${ }^{12}$ In cases of a conflict between the Act and provincial gambling legislation, the former prevails, provided it complies with the conditions set out by the Constitution regarding conflicts between national and provincial legislation. ${ }^{13}$

The main purpose of the Act is to provide for coordination and uniformity in the regulation of gambling activities between the National Gambling Regulator $^{14}$ and provincial licensing authorities ${ }^{15}$ through the establishment of norms and standards. ${ }^{16}$ The Act retains the National Gambling Regulator $^{17}$ while adding another statutory body, the National Gambling Policy Council. The Act, therefore, re-enacts many of the provisions contained in the repealed National Gambling Act of 1996, while adding several provisions that introduce new policies for the concurrent national and provincial regulation of gambling. ${ }^{18}$ More importantly, the preamble to the Act sets the tone for the introduction and application of the destination approach in the regulation of casino gambling.

National and Provincial Legislative Competence", lists in Part A "casinos, racing, gambling and wagering, excluding lotteries and sports pools", amongst others.

7 S 22 of the Constitution providing that "every citizen has the right to choose their trade, occupation or profession freely". "The practice of a trade, occupation or profession may regulated by law", which means if the trade, occupation or profession is prohibited by law, therefore it cannot be exercised. Gambling is decriminalised and therefore not prohibited.

8 According to PricewaterhouseCoopers "Taking the Odds: Gambling Outlook for 2015-2019" (South Africa-Nigeria-Kenya) 2015-12 https://www.pwc.co.za/en/assets/pdf/gamblingoutlook-2015-2019.pdf (accessed 2016-11-21) provincial spheres of government consider gambling to be one of their most important sources of revenue, with a combined gross gambling revenue totalling R17.2 billion (USD1.6 billion) in 2014 .

9 Carnelley "A Précis of the South African Gambling Industry" 2000 5(1) Gambling LR 3 3-4.

10 Hereinafter "the Act".

11 National Gambling Act 7 of 2004.

12 The provincial gambling laws include the Eastern Cape Gambling and Betting Act 5 of 1997; Free State Gambling and Liquor Act 6 of 2010; Gauteng Gambling and Betting Act 4 of 1995; KwaZulu-Natal Gaming and Betting Act 8 of 2010; Limpopo Gambling Act 3 of 2013; Mpumalanga Gaming Act 5 of 1995; North West Gambling Act 2 of 2001; Northern Cape Gambling Act 3 of 2008 and Western Cape Gambling Act 4 of 1996.

13 S 146 of the Constitution of the Republic of South Africa, 1996.

14 Previously National Gambling Board.

15 Also known as provincial gambling boards.

16 Preamble to the National Gambling Act 7 of 2004.

17 Established in terms of the repealed National Gambling Act, 1996.

18 Explanatory Memorandum to the National Gambling Bill, 2003. 


\section{APPLICATION OF THE DESTINATION APPROACH IN SOUTH AFRICA'S GAMBLING LAW}

The preamble to the Act affirms the protection of the "society and economy against over-stimulation of a latent demand for gambling", ${ }^{10}$ as one of the policy principles upon which the provision of gambling is regulated. Embedded in this policy principle is the desirability of limiting gambling opportunities, by locating casino gambling venues a distance away from society. ${ }^{20}$ Referred to as the "destination approach" by the gambling fraternity, the goal of this policy principle is "to reduce accessibility by vulnerable communities to convenience gambling by concentrating these opportunities in fewer dedicated gambling venues that require some effort and deliberate intention to visit."11 This has been the guiding policy principle in South Africa, particularly with regard to mostly casinos. The destination approach to gambling in South Africa was adopted in 1993 by the Howard Commission of Inquiry into Lotteries, Sports Pools, Fund-raising Activities and Certain Matters Relating to Gambling. According to the Commission, criteria for the granting of future casino licence(s) should include the condition that:

"The new facilities (i.e. casino facilities) ... should take the form of tourist resorts located at a reasonable distance (but not less than an hour's drive) away from metropolitan areas. The object is to try to satisfy the demand for casino gaming and minimise socially harmful excesses by placing it beyond the reach of people who cannot afford it."

The application of the destination approach to gambling in South Africa is largely credited for the establishment of casino holiday resorts throughout the country outside major city centres. ${ }^{23}$ However, these resorts remain artificial tourist attractions and many are facing extinction due to dwindling numbers of visitors, as patrons seem to be attracted to gambling venues located in entertainment or shopping centres. ${ }^{24}$ For its part, the destination approach is viewed as a harm minimisation measure in relation to problem

19 The Preamble to the National Gambling Act 7 of 2004 adds that "it is desirable to establish certain uniform norms and standards, which will safeguard people participating in gambling and their communities against the adverse effect of gambling, applying generally throughout the Republic with regard to casinos, racing, gambling and wagering, so that society and the economy are protected against over-stimulation of the latent demand for gambling".

20 Tyawa "Regulating Gaming in the New South Africa" 2012 16(1) UNLV Gaming Research and Review Journal 93 95, stating that South Africa has adopted a "sumptuary model whereby most gambling sites are a reasonable distance away from poorer areas" and Department of Trade and Industry National Gambling Policy 13.

21 Young et al Destination-Style Gambling 1.

22 Howard Commission South Africa Commission of Inquiry into Lotteries, Sports Pools, Fundraising Activities and Certain Matters Relating to Gambling (1993) 110-111.

23 Stern "Competition and Location in the Gaming Industry: the "Casino States" of Southern Africa" 1987 72(2) Geography 140 140-150. See also Tyawa 2012 16(1) UNLV Gaming Research and Review Journal 95 confirming the contribution of the casino industry to the construction of hotels and convention centres in major metropolitan cities in South Africa.

24 The Department of Trade and Industry National Gambling Policy 13, in which it is recognised that casino operators at times might find that areas in which they are located are no longer viable for them to compete and be profitable, concede to this fact. 
gambling, in the sense that the placement of gambling venues in remote areas will avert the risk of impulsive gambling. ${ }^{25}$ In other words, proximity to gambling venues will lead to inordinate gambling by regular gamblers and consequently contribute to problem gambling. ${ }^{26}$

In giving effect to the destination approach, the National Gambling Act, in conjunction with provincial gambling laws, ${ }^{27}$ make provision for the issuance of, amongst others, a gambling operator licence and licence for gambling premises, which are required for the operation of casino gambling. Although a gambling operator licence will entitle the licence holder to provide gambling activities listed therein, it is the licence for gambling premises that will specify the location where the gambling activities will take place, thereby giving effect to the goal of the destination approach. The licence holder is bound to operate his/her gambling activities in the stipulated location, which will also require approval for its suitability and compliance with the National Gambling Act. Authority for the issuance of casino licences (that is, both operator licences and licences for gambling premises) is vested with provincial licensing authorities. ${ }^{28}$ Recent developments regarding the National Gambling Amendment Act Bill of $2016^{29}$ indicate that provincial licensing authorities have the power to issue gambling licences, with the National Gambling Regulator ${ }^{30}$ assuming the role of a supervisor. ${ }^{31}$ However, the authority to determine the maximum number of licences to be issued by each provincial licensing authority remains with the Minister who has jurisdiction over gambling activities. ${ }^{32}$ Like any other principle, the purity of the destination approach remained suspect with certain casinos emerging

25 This view is also shared by Victorian Department of Justice Destination Gaming: Evaluating the Benefits for Victoria (2008) 1-2 which observed that findings in a number of research reports suggest that less gaming venues might reduce problem gambling by making it less likely that problem gamblers will attend venues on impulse alone.

26 Vasiliadis, Jackson, Christensen and Francis "Physical Accessibility of Gaming Opportunity and its Relationship to Gaming Involvement and Problem Gambling: A Systematic Review" 201328 Journal of Gambling Issues 137.

27 Eastern Cape Gambling and Betting Act 5 of 1997; Free State Gambling and Liquor Act 6 of 2010; Gauteng Gambling and Betting Act 4 of 1995; KwaZulu-Natal Gaming and Betting Act 8 of 2010; Limpopo Gambling Act 3 of 2013; Mpumalanga Gaming Act 5 of 1995; North West Gambling Act 2 of 2001; Northern Cape Gambling Act 3 of 2008 and Western Cape Gambling Act 4 of 1996.

28 Provincial gambling boards.

29 National Gambling Amendment Bill of 2016, GN 1207 in GG 40320 of 2016-09-30.

30 Formerly National Gambling Board.

31 S 19 of the National Gambling Amendment Bill of 2016 proposes an insertion to s 33 of the National Gambling Act 7 of 2004 dealing with the responsibilities of the National Gambling Regulator. The insertion proposes that: "The National Gambling Regulator is responsible to (a) evaluate -

(i) the issuing of national licences by provincial licensing authorities; and

(ii) the compliance monitoring of licensees by provincial licensing authorities.

(b) conduct oversight evaluations of the performance of provincial licensing authorities in the manner envisaged in S 34 , so as to ensure that the national norms and standards established by this Act are applied uniformly and consistently throughout the Republic."

32 S 45 of the National Gambling Act 7 of 2004 empowers the Minister through regulations to prescribe a maximum number. The current provisions allow the Minister to amend the prescribed maximum number of casino licences without amending the legislation. Currently, the casino licences issued across the country stand at 40 . 
in the middle of the towns such as Port Elizabeth and Pietermaritzburg. Moreover, licensing of gambling games such as slot machines and bingo in non-casino venues ${ }^{33}$ indicates a deviation from destination approach.

The preservation and maintenance of the destination approach is more pronounced in the National Gambling Policy of 2016 than the National Gambling Amendment Bill of 2016 that is the proposed legislative instrument. The former calls for the enhancing of casino regulation to ensure that the destination approach for the location of casinos is maintained. ${ }^{34}$ This is understandable given that not all policy objectives should result in legislative provisions. Some policy objectives require a direct application. In this regard, the National Gambling Regulator may ensure adherence to the destination approach through its role of evaluating gambling licences determined by provincial licensing authorities. ${ }^{35}$

\section{RELATIONSHIP BETWEEN THE DESTINATION APPROACH AND PROBLEM GAMBLING}

Problem gambling is often used interchangeably with gambling disorder or compulsive/pathological/addictive gambling. Problem gambling is a menace to the gambling sector, as it does not only compromise the financial stability of the gambler but also disrupts or damages personal, family or recreational pursuits. ${ }^{36}$ It is characterised by difficulties in limiting the time and money spent on gambling, which leads to adverse consequences for gamblers, such as financial instability, family disruption, stress, criminal behaviour and substance and drug abuse.

The National Gambling Policy of 2016 alludes to the relationship between the destination approach and problem gambling. It states thus:

"Introduction of online casino gambling requires a policy shift in regard to the destination approach to gambling as it proposes bringing gambling activities more closer to people. This aspect is considered against the concern regarding problem gambling in South Africa, and measures to combat it successfully. ... Other forms of gambling should remain illegal as the proliferation of gambling, rising levels of problem gambling, employment and

\footnotetext{
S 3-5 of the National Gambling Act.

Department of Trade and Industry National Gambling Policy 2.

35 The responsibilities of the National Gambling Regulator are discussed in fn 25 above.

36 National Gambling Board Socio-Economic Impact of Legalised Gambling in South Africa [Gambling behaviour in South Africa: Results from the 2009 socio-economic impact study] (2009) 39. See also Blaszczynski and Nower "A Pathways Model of Problem and Pathological Gambling" 2002 97(5) Addiction 487488 describing problem gambling as referring to a "situation when a gambling activity gives rise to harm to the individual gambler, and/or to his or her family, and may extend into the community". The authors added, "typically, gambling problems may arise as a result of differences of opinion regarding amounts potentially risked or time spent away from home/family in the absence of any excessive financial losses relative to disposable income, preoccupation with gambling, absent impaired control or other adverse consequences."

37 Australian Department of Justice Taking Action on Problem Gambling: A Strategy for Combating Problem Gambling in Victoria (2006) 7.
} 
inadequate enforcement capacity weigh more against any argument in support of lifting the ban on this activity at this point."

The underlying message in this policy statement is that by bringing gambling facilities and opportunities closer to communities, in contradiction of the destination approach, will cause more people to gamble impulsively, which will lead to problem gambling. Therefore, the destination approach is seen as an indirect means to prevent problem gambling. Unfortunately, the National Gambling Policy offers no evidence of the relationship between the destination approach and problem gambling. As noted by Ratio, ${ }^{39}$ the relationship between accessibility ${ }^{40}$ and problem gambling is not a simple or linear equation, as there are social, economic and environmental factors that need to be considered. Gambling reports or policy documents often take such a relationship for granted, without doing any scientific research.

\section{Prevalence of problem gambling in the midst of the destination approach}

South Africa's gambling regulatory framework acknowledges the existence of problem gambling. In terms of the National Gambling Act, the National Gambling Regulator must "research and identify factors relating to, and patterns, causes, and consequences of addictive or compulsive gambling". ${ }^{41}$ Relying on the South Oaks Gambling Screen to identify problem gambling, the then National Gambling Board classified gamblers according to four categories, namely: no-risk gamblers, low-risk gamblers, moderate risk gamblers and at-risk gamblers. ${ }^{42}$ An individual in the latter category is described as a gambler who has suffered from or experienced undue social or financial stress as a result of his/her gambling activities, that is, problem gambling.

By using this classification, the National Centre for the Study of Gambling released findings in 2006 on the prevalence rate of problem gambling in South Africa. It found that in 2003, problem gambling stood at $6.8 \%$ of the gambling population. ${ }^{44}$ By 2006 , the number had declined to $4.8 \% .{ }^{45}$ The last statistics published by the NGB show that by November 2012, problem gambling stood at $2.9 \%$ of the gambling population. ${ }^{46}$ Though this decline in problem gambling between 2003 and 2012 is a welcome relief, problem gambling still remains a concern for the gambling sector. Globally it is

\footnotetext{
Department of Trade and Industry National Gambling Policy 9.

Ratio Social and Economic Impact Assessment (2013) 30.

Which the destination approach is seen as limiting.

S 65 (1)(d)(ii) of the National Gambling Act 7 of 2004.

42 National Gambling Board "Gambling Trends and Patterns amongst the South African Population" 20121 Research Bulletin 3.

44 National Centre for the Study of Gambling The National 2006 Prevalence Study: Gambling and Problem Gambling in South Africa (2006) 15.

46 National Gambling Board "National Gambling Board Leads Tracking Gambling Research in South Africa" 20132 Research Bulletin 1.
}

43 Ibid.

45 lbid. 
reported that problem gambling ranges from $0.5 \%$ to less than $8 \%$, with many countries averaging $2-3 \%$.

\section{Effects of problem gambling}

In most cases, the effects of problem gambling extend beyond an individual gambler to family members, as well as the workplace and society. On average, it is estimated that the effects of problem gambling, per person, have an impact on 10-17 individuals, including family members and colleagues. ${ }^{48}$ The negative effects, which include domestic violence; substance and alcohol abuse; and criminal behaviour ${ }^{49}$, are briefly discussed below.

\section{Domestic violence}

Empirical research shows that domestic violence is more prevalent amongst problem gamblers than the general population. ${ }^{50}$ This is largely the result of financial strains placed on family resources by a partner, spouse or family member who is a problem gambler, and who becomes unable to discharge his/her obligations towards the family as a result of losing his/her income through gambling. The financial stress caused by gambling losses has the propensity to manifest itself within the family and may result in the perpetration of violence against family members. When Afifi et al analysed the relationship between gambling problems and the perpetration of intimate partner violence and child abuse, the authors found that, amongst the negative consequences of problem gambling, was an increase in the risk of dating violence, acute marital violence and aggravated child abuse. ${ }^{51}$ The discharge of violence is seen as an attempt by a gambler with a gambling problem to manage or maintain his/her own equilibrium. ${ }^{52}$ According to Suomi et al, the perpetration of domestic violence ${ }^{53}$ occurs as a "reaction to deeply rooted and accumulated anger and mistrust whereas victimisation is an outcome of a gambler's anger brought on by immediate gambling losses and frustration". ${ }^{54}$ The anger or frustration is a culmination of the financial stress caused by the loss of money through gambling.

47 Ibid.

48 Kalischuk, Nowatzki, Cardwell, Klein and Solowoniuk "Problem Gambling and its Impact on Families: A Literature Review" 2006 6(1) International Gambling Studies 3137.

49 Australian Gaming Council Current Issues Related to Identifying the Problem Gambler in the Gambling Venue (2002) 2627.

50 Korman, Collins, Dutton, Dhayananthan, Littman-Sharp and Skinner "Problem Gambling and Intimate Partner Violence" 2008 24(1) Journal of Gambling Studies 1314.

51 Afifi, Brownridge, MacMillan and Sareen "The Relationship of Gambling to Intimate Partner Violence and Child Maltreatment in a Nationally Representative Sample" 2010 44(5) Journal of Psychiatric Research 331.

52 Suissa "Gambling, Violence, and Family Dynamics: Some Intervention Markers" 2005 2(2) International Journal of Mental Health and Addiction 13.

53 Within the sphere of gambling.

54 Suomi, Jackson, Dowling, Lavis, Patford, Thomas, Harvey, Abbott, Bellringer, KoziolMcLain, and Cockman "Problem Gambling and Family Violence: Family Member Reports of 


\section{Substance and drug abuse}

Substance and drug abuse, as such, do not necessarily lead to gambling addiction but are often associated with gambling. ${ }^{55}$ Stewart and Kushner reveal the correlation between gambling and alcohol consumption, and point out that a large percentage of gamblers indulge in alcohol consumption during gambling. ${ }^{56}$ This is most often the case in casino gambling, as casinos have bars that give their patrons easy access to alcohol. ${ }^{57}$ Generally, the consumption of alcohol or drugs has an effect on a person's state of mind. If consumed during gambling, these substances may affect the gambler's ability to control his/her spending. If this becomes a habit for a gambler, it may lead to problem gambling. Commenting on the relationship between gambling and alcohol consumption, French, Maclean and Ettner noted that:

"The consumption of alcohol can influence gambling choices, making individuals more (less) likely to initiate (terminate) gambling and increasing the amount they are prepared to wager in a particular gambling session. Specifically, alcohol consumption may inhibit the proper evaluation of the costs and benefits of gambling, impair the ability to understand the rules of the game, and/or lead to an inflated confidence in the ability to win."

In a study published in 2010, which the National Responsible Gambling Programme in South Africa commissioned in order to determine, amongst others, the co-occurrence of problem gambling amongst persons with alcohol dependency, it was found that of the 82 persons with full-blown alcohol dependency (that is, alcohol abuse disorder), 15 (18\%) were also suffering from problem gambling; $23(28 \%)$ were classified as being at moderate risk of developing problem gambling; and $12(15 \%)$ were at lowrisk of developing problem gambling. ${ }^{59}$ The remainder were at no-risk of developing problem gambling.

Prevalence, Family Impacts and Family Coping" 2013 3(13) Asian Journal of Gambling Issues and Public Health 1.

55 According to Whyte and Dunning 2016 6(2) UNLV Gaming LJ 201 - "Problem gambling is significantly correlated with other risky behaviour in adults and adolescents, including substance use [and abuse as well as] mental health issues. Adult problem gamblers are five times more likely to have co-occurring alcohol dependence, four times more likely to abuse drugs, three times more likely to be depressed, eight times more likely to have bipolar disorder, three times more likely to experience an anxiety disorder [and are at greater risk for suicide]."

56 Stewart and Kushner "Recent Research on the Comorbidity of Alcoholism and Pathological Gambling" 2003 27(2) Alcoholism: Clinical and Experimental Research 285.

57 Ramirez, McCormick, Russo and Taber "Patterns of Substance Abuse in Pathological Gamblers Undergoing Treatment" 1983 8(4) Addictive Behaviour 425.

58 French, Maclean and Ettner "Drinkers and Bettors: Investigating the Complementarity of Alcohol Consumption and Problem Gambling" 2008 96(1-2) Drug and Alcohol Dependence 155156.

59 National Responsible Gambling Programme Summary of Basic Data from the National Urban Prevalence Study of Gambling Behaviour (2010) 81 


\section{Criminal behaviour}

Criminal behaviour has been confirmed as one of the by-products of problem gambling/gambling disorder. ${ }^{60}$ Gamblers diagnosed as problem gamblers are often found to be involved or have been involved in some form of criminal acts, such as theft, fraud, forgery or embezzlement, in order to finance their gambling. ${ }^{61}$ According to a theory that seeks to explain the motives of gamblers for resorting to criminal behaviour to fund their gambling spree, gamblers start using their savings before asking for advances in the form of loans or credit cards. "Faced with mounting financial difficulties and gambling related debts, when all these legal sources of gambling funds are exhausted, gamblers may resort to illegal activities to obtain money". ${ }^{62}$ Criminal behaviour remains one of the by-products of problem gambling.

This was the case in $S \vee N e{ }^{64}$ in which the latter staged an armed robbery and stole an amount of R32 595. Following his arrest, Nel pleaded guilty and was convicted of armed robbery. ${ }^{65}$ In mitigation of his sentence, $\mathrm{Nel}$ called a clinical psychologist, who testified that he (Nel) had been suffering from a gambling disorder since 1994. The court rejected his plea that "gambling had made drastic inroads into his ability to make rational decisions and should have been viewed on its own as a mitigating factor and was in the nature of things a substantial and compelling circumstance justifying the imposition of a sentence lower than the ordained minimum sentence". ${ }^{66}$ However, the court did not dismiss problem gambling as the root cause of criminal behaviour. It merely rejected the recognition of problem gambling as a defence.

\section{ASSESSING THE RELEVANCE OF THE DESTINATION APPROACH IN THE MODERN ERA OF GAMBLING}

Noble as it may seem, maintaining the destination approach at all costs has the negative effect of suppressing new forms of gambling, such as

60 Clark and Walker "Are Gamblers More Likely to Commit Crimes? An Empirical Analysis of a Nationally Representative Survey of US Young Adults" 2009 9(2) International Gambling Studies 119 128-132.

61 Moss "Shuffling the Deck: The Role of the Courts in Problem Gambling Cases" 2016 6(2) UNLV Gaming LJ 145148.

62 Crofts "Problem Gambling and Property Offences: An Analysis of Court Files 2003 3(2) International Gambling Studies 183193.

63 Clark and Walker 2009 9(2) International Gambling Studies 119 and Turner, Preston, Saunders, McAvoy and Jain "The Relationship of Problem Gambling to Criminal Behaviour in a Sample of Canadian Male Federal Offenders" 2009 25(2) Journal of Gambling Studies 153 conclude in their study concerning the relationship between problem gambling and criminal behaviour that players with a gambling addiction were "significantly more likely to have committed income producing offences, but were neither more nor less likely than other offenders to have committed violent offences".

$64 S v$ Nel 2007 (2) SACR 481 (SCA).

$65 S \vee$ Nel supra par 4.

$66 \quad S \vee N e l$ supra par 13.

$67 \quad S \vee \mathrm{Nel}$ supra par 16 
interactive gambling, which does not require any physical location for accessibility. Internet gambling denotes gambling activities adaptable to the use of computer software and interactive communication. ${ }^{68}$ With this mode of gambling (that is, interactive gambling), access to the internet is sufficient to enable gamblers to indulge in gambling, thereby bringing gambling not only closer to people but even into the household and workplace of gamblers. ${ }^{69}$ However, interactive casino gambling remains prohibited in South Africa ${ }^{70}$ as its introduction is likely to bring gambling activities closer to people and necessitate a policy shift in regard to the destination approach to gambling. Notwithstanding the prohibition of interactive gambling, the National Gambling Policy of 2016 has brought the sustainability of the destination approach under the spotlight, which concedes that its adoption is no longer financially viable. In other words, the business model of keeping casino venues a distance away from communities is unprofitable, as patrons, in general, are attracted to shopping centres that house entertainment centres. It conceded thus:

"It is recognised that casino operators at times might find that areas in which they are located are no longer viable for them to compete and be profitable; however, relocating to areas close to where people live or shop undermines the destination approach to gambling."

On the ground, casino operators are indeed relocating to business areas - in other words, closer to communities, where their casino business is integrated into new shopping centres. For instance, in the Province of Gauteng, the Gauteng Gambling Board granted approval for the relocation of one of Sun International's casinos from Mabopane (Morula Sun) to Menlyn in the leafy suburbs of eastern Pretoria. ${ }^{72}$ In the Western Cape Province, the provincial gambling board was reported to be assessing the application for relocation of one of its existing casino licences located on the

68 Rose, Martin and Owens Internet Gaming Law 2ed (2009) 27. In South Africa's legal parlance, internet gambling involves a gambling game played or available to be played through the mechanism of an electronic agent accessed over the internet other than a game that can be accessed for play only in licensed premises, and only if the licensee of any such premises is authorised to make such a game available for play - $s 1$ of the National Gambling Act 7 of 2004.

69 For this purpose, see McMillen J "Online Gambling: Challenges to National Sovereignty and Regulation" 2000 18(4) Prometheus 391 392, in which he argues that interactive gambling delivers two forms of gambling, namely interactive wagering/betting and virtual interactive gaming. He argues that the former is not a new form of gambling, but merely technological developments allowing bets to "be made interactively in 'real time' so that a gambler can bet on various events within a game, rather than waiting for the final result". On the other hand, interactive gaming is indeed a new form of gambling, made possible only by computer technology. He adds, "interactive gaming/games are not played in a physical location but instead are generated by computer software and results are determined by a randomnumber generator on the operator's server". See also Tyawa 2012 16(1) UNLV Gaming Research and Review Journal 95-96 regarding the inevitable benefits of electronic communication technology, which introduces a new platform for gambling. Tyawa argues that such advancements in electronic communication technology may necessitate both policy and legislative changes to accommodate new delivery modes.

70 Casino Enterprises (Pty) Ltd v Gauteng Gambling Board 2011 (6) SA 614 (SCA) par 40.

71 Department of Trade and Industry National Gambling Policy 13.

72 Gauteng Gambling Board Annual Report 2014/2015 19. 
outskirts of the city centre to the Cape Metropole. ${ }^{73}$ Relocation, as well as developments around or nearby casino venues, marks the beginning of the demise of the destination approach. Though the National Gambling Policy calls on provincial licensing authorities to assess policy implications when presented with a request for the relocation of casino venues from one area to another, ${ }^{74}$ it is doubtful whether this can be maintained, especially with clear evidence pointing to the destination approach being no longer economically viable.

In its presentation of the National Gambling Policy to the Portfolio Committee on Trade and Industry, the Department of Trade and Industry revealed that there are numerous developments, such as housing and shopping malls, around casino precincts that "begin to impact on the destination approach policy". ${ }^{75}$ To circumvent this impact, the aforesaid department proposed that, "entrances and exits for casinos remain distinct from other developments around it". ${ }^{\text {" }}$ The development around casino precincts is an unwitting attack upon the destination approach's goal of keeping casino facilities a distance away from residential areas.

In general, little evidence exists to support the usefulness of the destination approach in preventing problem gambling. The closest research available regarding the physical accessibility of gaming opportunities and its relationship to gaming involvement and problem gambling involved electronic gaming machines, both in the casino and non-gaming venues. ${ }^{77}$ Although the study found an association between proximity to gambling and problem gambling, it noted that "adaptation to gambling opportunities over time lead to decreased interest", thereby decreasing gambling involvement. ${ }^{78}$ Unfortunately, South Africa has never conducted research on the efficacy of the destination approach in combatting problem gambling in either casino or non-casino venues. Therefore, the National Gambling Policy takes it for granted that the destination approach has a natural effect of reducing problem gambling by keeping gambling venues a distance away from communities.

Gambling regulators all over the world are constantly developing or reviewing their strategies for the minimisation and/or prevention of problem gambling. Key to these strategies are self-limit measures, which include the option of setting daily, weekly or monthly limits on the size of deposits; setting a system-wide loss or time limit; setting individual loss or time limits for each type of game offered by the site; time-out when the limit is reached;

73 Tsogo Sun Integrated Annual Report (2015) 18. The report further notes that the Western Cape licensing authority is considering the relocation of its existing Western Cape casino licence to the Cape Metropole.

74 Department of Trade and Industry National Gambling Policy 2.

75 Department of Trade and Industry "National Gambling Policy - Recent Presentation to the Portfolio Committee" 2016-03-09 slide 7 https://www.thedti.gov.za/parliament/2015/ Draft_ Gambling_Policy_Review.pdf (accessed 2016-10-17).

76 Ibid.

77 Vasiliadis et al 201328 Journal of Gambling Issues 1.

78 Vasiliadis et al 201328 Journal of Gambling Issues 26.

79 Department of Trade and Industry National Gambling Policy 9. 
and more importantly, self-exclusion from participation in gambling. ${ }^{80}$ Other measures include prevention, education, treatment, enforcement research, responsible gambling and recovery. ${ }^{81}$ Responsible gambling and recovery encapsulate the self-limit measures outlined above. ${ }^{82}$ This means that the destination approach, on its own, is neither a tool nor a strategy for the minimisation or prevention of problem gambling.

\section{CONCLUSION}

In South Africa, the destination approach is credited for the development and increase of casino gambling venues, which serve as tourist attractions. Indeed, casino gambling takes the lion's share of legalised gambling activities in the country. Equally so, casino gambling is responsible for the existing levels of problem gambling, despite its locations being a distance away from communities. However, times and circumstances have changed, with gambling business strategies being geared towards profit maximisation. The financial viability of casino gambling, anchored on the destination approach, is now under threat, with casino operators seeking to relocate their businesses to the areas of business development, and integrating their casinos into shopping and entertainment centres. On the other hand, gambling is no longer restricted to casino venues. There are numerous noncasino platforms for conducting gambling, such as electronic bingo terminals and interactive (the latter is currently prohibited), which render the destination approach obsolete. More importantly, the destination approach is neither a strategy nor a tool for the prevention of problem gambling. Other than limiting accessibility to gamblers with no means of transport to casino venues, its impact on problem gambling is more complex than one can imagine. Using the destination approach as a means to avert problem gambling makes a mockery of the proven strategies for the reduction of problem gambling.

Both the National Gambling Policy of 2016 and the National Gambling Amendment Act Bill of 2016 can still achieve their policy objectives without the destination approach, rather than using the latter as an impediment to new forms of gambling, such as interactive/online gambling. The latter is merely a subset of gambling or electronic version of casino gambling, with a safeguard for problem gambling. The only reasonable justification for continuous adherence to the destination approach is to shield existing casino gambling from competing with new forms of gambling. To this extent, the application of the destination approach hampers the realisation and enjoyment of gambling as a constitutionally recognised activity for recreational economic purposes, which should benefit both the national and provincial governments.

\footnotetext{
80 See Williams, West and Simpson Prevention of Problem Gambling: A Comprehensive Review of the Evidence and Identified Best Practices Report prepared for the Ontario Problem Gambling Research Centre and the Ontario Minister of Health and Long Term Care (01 October 2012).

81 Whyte and Dunning 2016 6(2) UNLV Gaming LJ 203.

82 Whyte and Dunning 2016 6(2) UNLV Gaming LJ 218.
} 